\title{
Neuroprotective Effect of Vanda roxburghii Extract in Endothelin-1 (et-1) Induced Hippocampal Ischemic Damage and Ameliorate Cognitive Deficit
}

\author{
Ravi Mundugaru ${ }^{1 *}$, Sukrant Sharma ${ }^{2}$, Senthilkumar Sivanesan ${ }^{3}$, Rajesh Thangarajan $^{4}$, \\ Pundalik Rama Naik ${ }^{5}$, Nagesh Raju${ }^{1}$, Ahmed Alfarhan ${ }^{6}$, Rajakrishnan Rajagopal ${ }^{6}$, Bander AlMunqedhi ${ }^{6}$ \\ ${ }^{1}$ Department of Pharmacology, DM Wayanad Institute of Medical Sciences, Wayanad, Kerala, INDIA. \\ ${ }^{2}$ Department of Shalya Tantra, JIAR, Jammu and Kashmir, INDIA. \\ ${ }^{3}$ Department of Research and Development, Saveetha University, Chennai, Tamil Nadu, INDIA. \\ ${ }^{4}$ Department of Anatomy, Melaka Manipal Medical College, Manipal, Karnataka, INDIA. \\ ${ }^{5}$ Department of Biochemistry, Kodagu Institute of Medical Sciences, Madikeri, Karnataka, INDIA. \\ ${ }^{6}$ Department of Botany and Microbiology, College of Science, King Saud University, Riyadh, SAUDI ARABIA.
}

\begin{abstract}
Introduction: The concept of neuroprotection gaining considerable interest in search for novel therapy that has potential to preserve brain tissues and improve cognitive functions in ischemic brain damage. In the present study we evaluated the neuroprotective efficacy of hydro alcoholic extract of Vanda roxburghii in experimental models of ischemic hippocampal injury in rats. Materials and Methods: Ischemic hippocampal injury was induced by single intra-hippocampal injection of Endothelin-1 $(80 \mu \mathrm{M})$ using stereotaxic instrument. Following ischemic hippocampal damage, hydro alcoholic extract of Vanda roxburghii (HAVR) (200 and $400 \mathrm{mg} / \mathrm{kg}$ ) was administered orally, once in a day for 14 consecutive days. Results and Discussion: The Morris water maze, Actophotometer and Open field behavioral test results showed significant cognitive deficit after ischemic hippocampal damage, however the repeated administration of HAVR at higher dose level for 14 consecutive days attenuated the cognitive deficits to a significant level. The histopathological examination of CA1 and CA3 regions of hippocampus revealed the loss of normal pyramidal cells and degenerative changes with shrunken, hyperdensed soma with pyknotic nuclei, however HAVR treatment at both dose levels significantly attenuated the observed qualitative changes. HAVR treatment showed significant anti-oxidant properties by inhibiting lipid peroxidation in ischemic condition as well as restoration of glutathione peroxidase enzymes to significant level. Conclusion: The study concludes that $V$. roxburghii extract and its constituents have neuroprotective potentials in ischemic hippocampal injury.
\end{abstract}

Key words: Stereotaxic, Hippocampus, Pyramidal cells, Morris water Maze, Lipid peroxidation.

\section{INTRODUCTION}

The incidence of ischemic stroke and stroke related dementia are high in recent years. Globally stroke is the third leading cause of death after cardiovascular disease and cancer. ${ }^{1,2}$ The impairment of blood flow to the vital areas of brain results in ischemic brain damage. Around the ischemic area the there is a high chance of accumulation of excitatory neurotransmitters and calcium ions. This results in cascade of reactions such as oxidative stress, inflammation, cellular apoptosis and degeneration., The main drawback in the treatment of stroke is lack of efficient therapeutic alternatives. This motivates research efforts to identify the mechanisms of neuronal death and to discover new therapeutic approaches to combat those. ${ }^{2}$ In the traditional system of medicine like Ayurveda, many herbs are mentioned for their therapeutic utility
Submission Date: 05-01-2020; Revision Date: 30-03-2020; Accepted Date: 30-04-2020

DOI: 10.5530/ijper.54.3.125 Correspondence:

Dr. Ravi Mundugaru Assistant Professor, Department of Pharmacology, DM Wayanad Institute of Medical Sciences,

Wayanad, Kerala, INDIA. Phone: +91 9986118401 E-mail: ravisdm13@gmail. com

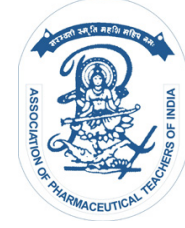

www.ijper.org 
in neurodegenerative disorders and in recent years researchers have focused much in exploring medicinal plants for their neuroprotective actions. ${ }^{5}$

In Ayurveda the plant species such as Pluchea lanceolata, Alpinia galanga and Vanda roxburgbii R.Br. (Orchidaceae) are considered to be Rasna source plants and are used for the treatment of pain, inflammation, arthritis, sciatica and neurological disorders. According to Ayurveda, Rasna is considered as Agrya Dravya (supreme drugs) for the management of neurodegenerative conditions and are constituents of 120 herbal formulations used for treating of chronic and acute illness. Some of the important formulations are Rasna erandadi kashaya, Rasna saptaka kashaya, Rasnadi guggulu, Maharasnadi kashaya, Dadhika gritha and Rasnadi choorna. ${ }^{6}$ Although it has been used as one of the important ingredients in different polyhedral formulation, its neuroprotective efficacy was not yet evaluated in animal model and hence it is important to explore the efficacy of this herbal drug in ischemic brain injury. In the present study, investigations were done to determine if HAVR could exert neuroprotection against experimental focal cerebral ischemia in rats by using histological, biochemical and cognitive assessment studies.

The plant is known as Rasna in Sanskrit, Banda, Persara in Hindi and Bandanike in Kannada. It is mainly distributed in India, Maynmar, Srilanka and Bangladesh, commonly known as Vanda orchid. Vanda is widely used in the treatment of fever, dyspepsia, bronchitis, inflammation, diseases of abdomen, hiccough, tremors liver diseases, rheumatoid arthritis and sciatica as a nerve tonic in diseases of nervous system. ${ }^{7,8}$ The plant extract has been reported to possess several pharmacological activities such as anti-inflammatory, analgesic, anti-arthritic, antioxidant, wound healing, anti-diarrheal and hepatoprotective activities. 'The root of the plant is useful in rheumatism and allied diseases and it is prescribed in the decoction or paste forms. It is used as an important component of many medicated oils for external application in diseases such as rheumatism and nervous disorders. The leaf paste of this plant is applied to the body during fever and the juice is instilled into the aural meatus as a remedy for otitis media. Decoction of the roots of $V$. roxburghii is used in case of hemiplegia and sciatica. ${ }^{9}$ It has been reported that the ethanolic extract of roots of the plant $V$. roxburgbii has potent anticonvulsant activities by inhibiting maximal electric shock induced seizures, pentylenetetrazole and picrotoxicn induced seizures in mice. ${ }^{10}$ The plant contains alkaloids, glycosides, tannins, saponins, sterols, fatty oils, resins and coloring materials. The dried herb contains active constituents such as $\beta$ - sitosterol, $\lambda$-sitosterol and found to possess potent anti-inflammatory activities. ${ }^{11}$ The methanolic extract of $V$. roxburgbii possesses potent anti- oxidant, analgesic and anti-inflammatory activities. ${ }^{12-15}$ It has been shown that increased reducing power, nitric oxide and free radical scavenging activity of $V$. roxburgbii increases with the concentration. ${ }^{16-17}$ The methanol extract of the plant root showed significant anti-inflammatory activity in carrageenan induced inflammation in rats. ${ }^{14}$ The chloroform extract of $V$. roxburghii showed strong antioxidant power and free radical scavenging activity against 2, 2-diphenyl-1-picrylhydrazyl (DPPH) and hydroxyl free radicals and the antioxidant effect was further confirmed by significant inhibition of lipid peroxidation in rat brain homogenates. ${ }^{10}$ The phenolic content of chloroform extract of $V$. roxburghii exhibited significant antioxidant and inhibition of acetyl cholinesterase and butyryl cholinesterase enzymes. Thus it may have potentials to treat Alzheimer's disease. ${ }^{18}$ Thus several of these pharmacological activities support the use of HAVR in the management of ischemic brain injury.

Present study investigated the neuroprotective role of hydro alcoholic extracts of $V$. roxburghii in experimental model of ischemic hippocampal injury, were considerable cognitive impairment and damage to the hippocampal tissue morphology observed. The parameters were selected to assess the anti-oxidant efficacy, reversal of neuronal degeneration and memory impairment.

\section{MATERIALS AND METHODS}

\section{Plant material and extract preparation}

Vanda roxburgbii plants were distributed in the Western ghat area near Dharmasthala $\left(12.951^{\circ} \mathrm{N} 75.371^{\circ} \mathrm{E}\right)$, on the banks of Nethravathi River in the Belthangadi taluk of Dhakshina Kannada district in Karnataka, India. The plant materials were collected during the month of March 2015 and authenticated by Dr. Sunil Kumar Narayanan, a Senior Research Officer in the department of Pharmacognosy at Sri Dharmasthala Manjunatheshara Centre for research in Ayurveda and Allied Sciences, Udupi, India. The voucher specimen (SDMCRAAS17032302) was deposited at the herbarium of SDMCRA, Udupi for future references.

The plants were dried under shade and powdered using pulverizer at Sri Dharmasthala Manjunatheshwara Pharmacy, Udupi. Thereafter, $500 \mathrm{~g}$ of the coarse plant powder was soaked in $2 \mathrm{~L}$ of equal quantities of ethyl alcohol and cold distilled water for $24 \mathrm{~h}$ at the room temperature. The extract was concentrated by evaporating filtrate on water bath till free from water. 


\section{Experimental Animals}

The experiment was conducted after obtaining approval from Institutional Animal Ethical Committee at SDM Ayurveda College, Udupi, India (SDMCAU/ IAEC/ PH01/2014-15). In the present study we used male Wistar albino rats weighing 250-300g body weight. Rats were maintained at a temperature $25 \pm 20^{\circ} \mathrm{C}$, humidity of $50-55 \%$, natural light and dark cycle with commercial rat pellet diet supplied by Sri Durga Feeds, Bengaluru and water ad libitum.

\section{Animal grouping and treatment with HAVR}

Wistar albino rats were randomly grouped into 4 different categories, each with 12 rats. Group I (Vehicle control) rats were administered with $0.5 \%$ carboxyl methyl cellulose orally for 14 consecutive days. Group II (Endothelin-1 control) rats were treated with 0.5\% carboxyl methyl cellulose orally for 14 consecutive days followed by single intrahippocampal injection of 80 $\mu \mathrm{M}$ Endothelin-1 prepared in $0.1 \mathrm{M}$ phosphate buffer saline, pH7.4. Group III and IV (Test group) rats were administered with HAVR 200 and $400 \mathrm{mg} / \mathrm{kg}$ body weight prepared in $0.5 \%$ carboxyl methyl cellulose for 14 consecutive days (p.o) after single intrahippocampal injection of $80 \mu \mathrm{M}$ ET-1.

\section{Endothelin-1 induced ischemic hippocampal injury}

Rats were anaesthetized with single intraperitonial injection of Pentobarbitone ( $45 \mathrm{mg} / \mathrm{kg}$ body weight) followed by the crown of the head was shaved and cleaned with $70 \%$ alcohol. Then the rat was fixed to the stereotaxic instrument (Steolting, USA) for surgical procedures. The bregma point on the skull was located by making a midline incision and removing connective tissues using cotton swab. On the right side of the skull a small hole was drilled at unilateral coordination from the bregma point (anteroposterior: $4.5 \mathrm{~mm}$; mediolateral: $4.0 \mathrm{~mm}$; dorsoventral: $3.5 \mathrm{~mm}$ from the skull surface). Infusion syringe (23 gauge size, Hamilton, USA) was loaded with ET-1 $(80 \mu \mathrm{M}$ in phosphate buffer saline) was fixed to the stereotaxic instruments and lowered through the drilled hole targeting right hippocampal region. Three microliters of $80 \mu \mathrm{M}$ ET-1 was infused at a rate of $1 \mu \mathrm{L}$ per minute and the syringe was left in the place for three minutes after the infusion and then slowly removed. Under aseptic condition the incision was sutured and rats were placed in a dry and warm place with free access to soft food and water. ${ }^{19-21}$

\section{Behavioral evaluation for hippocampal function Open field behavioral test}

The exploratory behaviors such as number of rearing, grooming behavior, number of fecal pellet expelled and number of squares crossed were recorded on $14^{\text {th }}$ days of ischemic hippocampal injury using a special apparatus consisting of $96 \mathrm{~cm}^{2}$ in dimension with side walls measuring $30 \mathrm{~cm}$ in height. The floor of the box was divided into 36 equal squares. Each rat was placed at predetermined area and allowed it to explore the arena for 5 minutes duration. ${ }^{22}$

\section{Digital Actophotometer test}

Digital Actophotometer test was used to assess the spontaneous motor activities of rats after ischemic hippocampal injury. The rats were observed for five minutes duration, during which the number of times the rats crossed the light beam in the $\mathrm{X}$ and $\mathrm{Y}$ axis inside the Actophotometer chamber were recorded. ${ }^{23}$

\section{Morris water maze test}

Morris water maze test was conducted to assess the spatial acquisition memory after ischemic hippocampal damage and considered as most valuable tool to assess learning and memory in rodents. ${ }^{24,25}$ Morris water maze consists of a circular water tank having $150 \mathrm{~cm}$ in diameter and side walls of $40 \mathrm{~cm}$ in height. It is divided into four equal quadrants and designated as North west (NW), South west (SW), North east (NE) and South east (SE). A escape platform measuring $10 \mathrm{~cm}$ in diameter was placed in NW quadrats, $2 \mathrm{~cm}$ below the water level and maintained constantly in the same quadrant throughout the acquisition trials. During initial trial the rats which fail to recognize the hidden platform within 60 seconds was trained and allowed to stay on the hidden flat form for $15 \mathrm{sec}$ more. Thus each rat undergo four acquisition trial per day for four consecutive days and rats which fail to reach platform within $20 \mathrm{sec}$ on fourth trail day was excluded from the study. On fifth day, the escape platform was removed and retention trial was conducted. To evaluate the memory consolidation, retention trial was repeated on $14^{\text {th }}$ day of experimentation and the following parameters were recorded, time to reach target quadrant (NW latency), hidden platform (escape latency), latency to find the northwest and time spent in 
target quadrant $(\mathrm{NW})$ during retention trials were noted and evaluated. ${ }^{26}$

\section{Antioxidant tests}

Brain tissues were dissected out and cleaned with ice cold saline and homogenized in $0.1 \mathrm{M}$ phosphate buffered saline of $\mathrm{pH} 7.4$ and centrifuged at 4C. The supernatant was collected and subjected to assessment of various antioxidant parameters using standard protocols. The catalase (CAT) activity in the brain tissue was expressed as micromoles of $\mathrm{H}_{2} \mathrm{O}_{2}$ consumed/mg protein /min. ${ }^{27}$ The level of lipid peroxidation was expressed as milli moles of malondialdehyde (MDA) formed/g of wet tissue. ${ }^{28}$ Glutathione peroxidase (GSH-Px) activities were expressed as micro molar glutathione utilized per $\mathrm{mg}$ protein per minute at $37^{\circ} \mathrm{C} .{ }^{29}$

\section{Histopathology of hippocampal region of the brain}

The degree of neuronal survival in the CA1 and CA3 regions of hippocampus were carried out using Cresyl violet staining technique. After completing behavioral tests rats were euthanized using single intraperitonial injection of pentobarbitone $100 \mathrm{mg} / \mathrm{kg}$ body weight. Immediately the whole brain tissue was dissected out and transferred to $10 \%$ formalin followed by embedded in paraffin. Using rotary microtome (Leica RM 2155, Germany) $8 \mu \mathrm{m}$ thickness coronary sections were cut. The sections were stained with 1\% Cresyl violet staining using standard procedure. ${ }^{30}$ All slides were observed under light microscope (ZEISS Axio lab A1, Germany). The qualitative and quantitative estimation of live pyramidal cell population were carried out at CA1 and CA3 regions of hippocampus. The surviving neurons from all the groups in the CA1 and CA3 regions were quantified in $1 \mathrm{~mm}^{2}$ area focused using Axio cam ERc $5 \mathrm{~s}$ (ZEISS, Germany) software. The total number of normal neuronal cell bodies with normal cell membrane, nucleus with even staining was assessed. Sections were also evaluated for presence of darkly stained, irregular and shrunken pyramidal cells with pyknotic nuclei.

\section{Statistical analysis}

Data was expressed as Mean \pm SEM, analyzed by one way ANOVA followed by Dunnet's multiple comparison tests as post hoc test using Graph Pad prism Software, Inc., USA (version 3.1). A $p<0.05$ was considered as statistically significant.

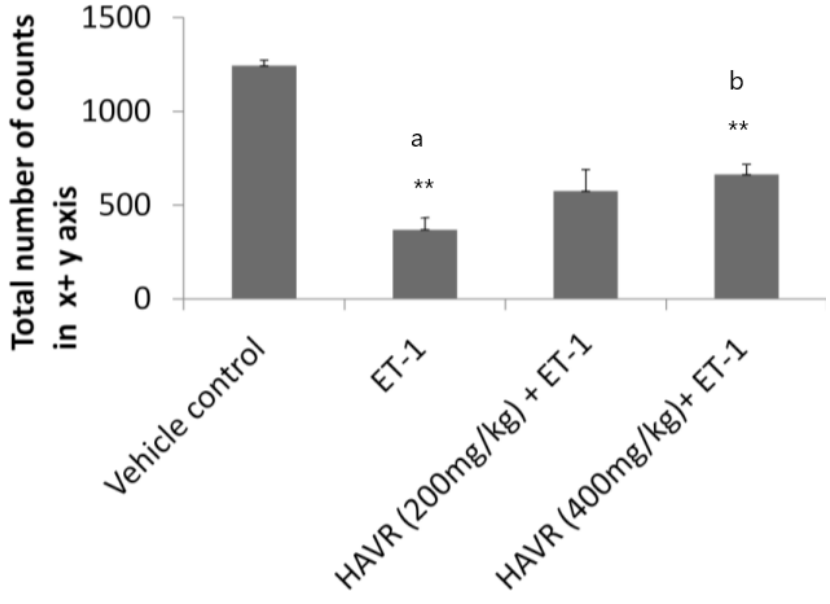

Figure 1: Actophotometer test performed in vehicle control, ET-1 control and ET-1 +HAVR drug (200 and $400 \mathrm{mg} / \mathrm{kg}$ ) treatment groups. The spontaneous motor activity was estimated by estimating total number of counts in $X$ and $Y$ axis. HAVR- Hydro alcoholic extract of Vanda roxburghii. ${ }^{*} p<0.01$, a- in comparison with vehicle control, "* $p<0.01$, b- in comparison with ET-1 control.

\section{RESULTS}

\section{Effect of HAVR drug on spontaneous motor activity in Actophotometer test}

The spontaneous motor activity was significantly reduced after ischemic hippocampal injury as compared to the vehicle control. Post ischemic treatment with HAVR at $400 \mathrm{mg} / \mathrm{kg}$ body weight dose significantly restored the spontaneous motor activity as compared to ischemic control group (Figure 1).

\section{Effect of HAVR drug on open field exploratory behaviors}

The open field exploratory behaviors such as number of squares crossed, number of rearing behavior were significantly reduced after ischemic hippocampal injury, whereas the number of fecal pellet expelled was significantly increased after ischemic hippocampal damage as compared to vehicle control. The grooming behavior was not significantly altered after ischemic hippocampal damage (Figure 2A, 2C and 2D). Post ischemic treatment with HAVR for 14 consecutive days significantly improved the open filed exploratory behavior as compared to ischemic control group (Figure 2B, 2C)

\section{Effect of HAVR in Morris water maze test}

ET-1 induced ischemic hippocampal damage significantly increased the NW latency (Figure 3A), escape latency (Figure 3B) and significant reduction in the time spent 

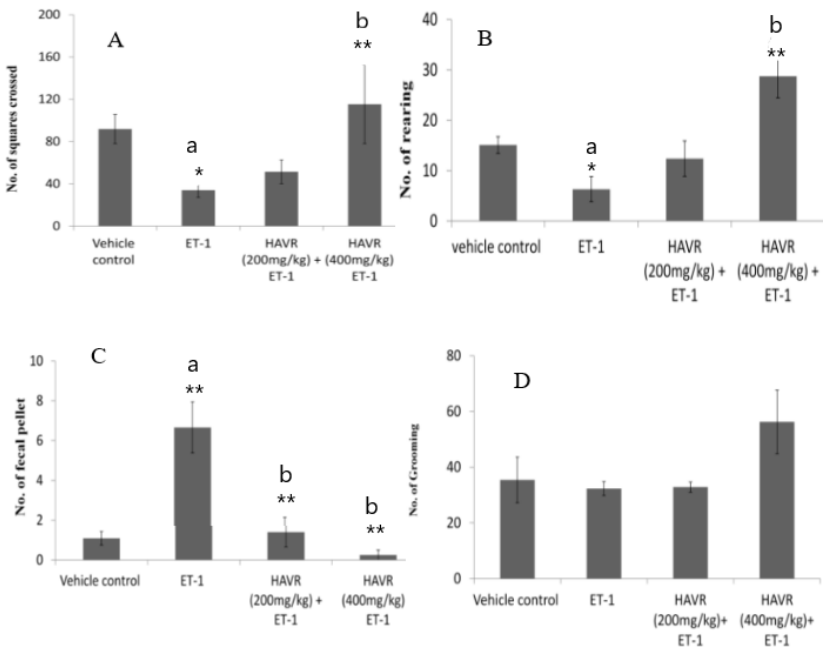

Figure 2: Rat behavioral studies were assessed in open field test in vehicle control, ET-1 control and ET-1 +HAVR drug (200 and $400 \mathrm{mg} / \mathrm{kg}$ ) treatment groups. The assessment of locomotor activity by movement (A), number of squares crossed (B), rearing behavior (C), number of fecal pellet expelled (D), grooming behavior, are shown respectively.

HAVR- Hydroalcoholic extract of Vanda roxburghii.

${ }^{* *} p<0.01,{ }^{*} p<0.05$, a- in comparison with vehicle control, b- in comparison with ET-1 control.
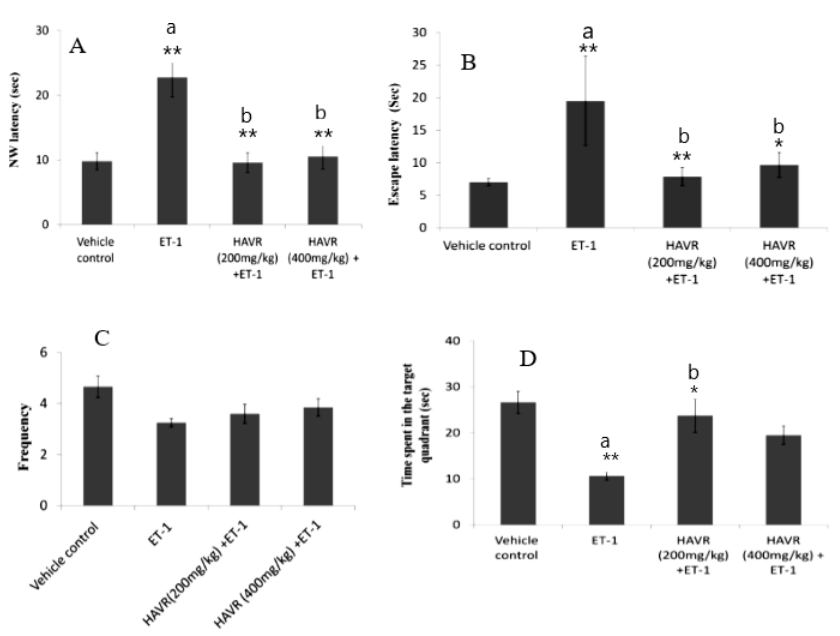

Figure 3: Morris water maze test performed in vehicle control, ET-1 control and ET-1 +HAVR drug (200 and $400 \mathrm{mg} / \mathrm{kg}$ ) treatment groups. The assessments of learning and memory by estimating northwest latency $(A)$, escape latency $(B)$, frequency $(C)$ and time spent in target quadrant (D) are shown respectively. HAVR- Hydroalcoholic extract of Vanda roxburghii.

${ }^{* *} p<0.01,{ }^{*} p<0.05$, a- in comparison with vehicle control, b- in comparison with ET-1 control.

in the target quadrants as compared to the vehicle control (Figure 3D). HAVR treatment at both dose levels significantly decreased NW latency (Figure 3A), escape latency (Figure 3B) and significantly increased time spent in the target quadrants as compared to the ischemic control (Figure 3A, 3C)

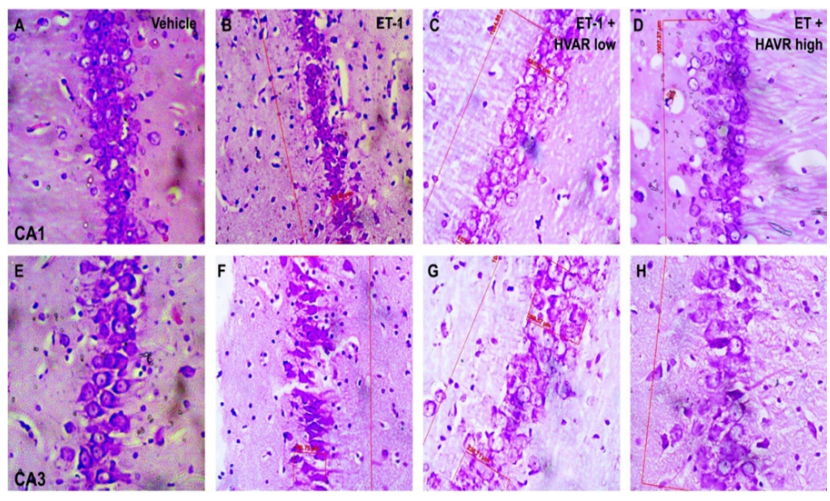

Figure 4a: Photomicrographs of cresyl violet stained CA1 and CA3 hippocampal pyramidal cells across different treatment groups $(A-H)$. Vehicle control group rats showed compactly arranged healthy pyramidal cells in CA1 (A) and CA3 (E) hippocampal sub regions. There were shrunken hyperdensed cells with pyknotic nuclei in ET-1 group (B) and (F). Recovery in intactness of pyramidal cell layer with normal neuronal morphology after HAVR treatment, both in the CA1 and CA3 subdivisions of the hippocampus (compare $C$ and $D$ with $B$ and $G$ and $H$ with $F$ ).
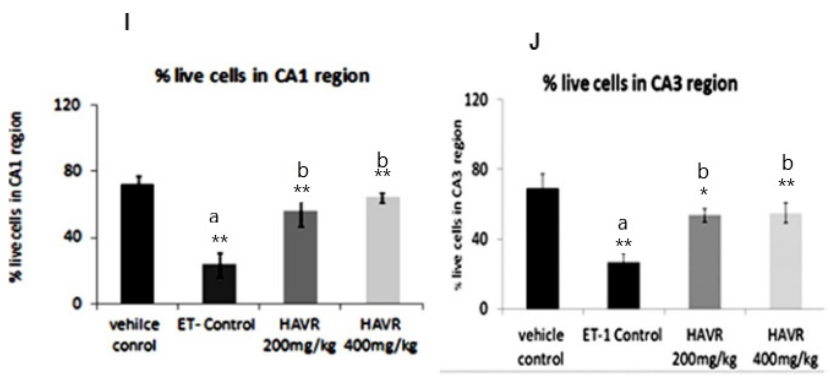

Figure 4b: Ischemic hippocampal injury caused significant reduction in the pyramidal cells in CA1 $(\mathrm{I})$ and CA3 $(\mathrm{J})$ sub-regions of hippocampus. HAVR treatment significantly attenuated ischemic damage by increasing percentage live cells at CA1 and CA3 sub regions of hippocampus.

${ }^{*} p<0.01,{ }^{*} p<0.05$, a- in comparison with vehicle control, b- in comparison with ET-1 control.

Effect of HAVR on percentage live pyramidal cells of the CA1 and CA3 regions in ET-1-induced ischemic injury

Histopathological examination revealed there were compactly arranged healthy pyramidal cells with prominent nauseous and intact cell membrane in CA1 and CA3 regions of hippocampus in vehicle control rats (Figure 4A, E). ET-1 induced ischemic hippocampal injury caused significant reduction in the healthy pyramidal cells in the CA1 and CA3 regions and increased darkly stained, irregular shaped shrunken pyknotic cells with large number of ectopic nuclei cells (Figure 4 B, F). HAVR treatment at both dose levels were well preserved the normal morphology of pyramidal cells (Figure 4, compare C and D with B and $\mathrm{G}$ and $\mathrm{H}$ with F). Quantification analysis of cell number 


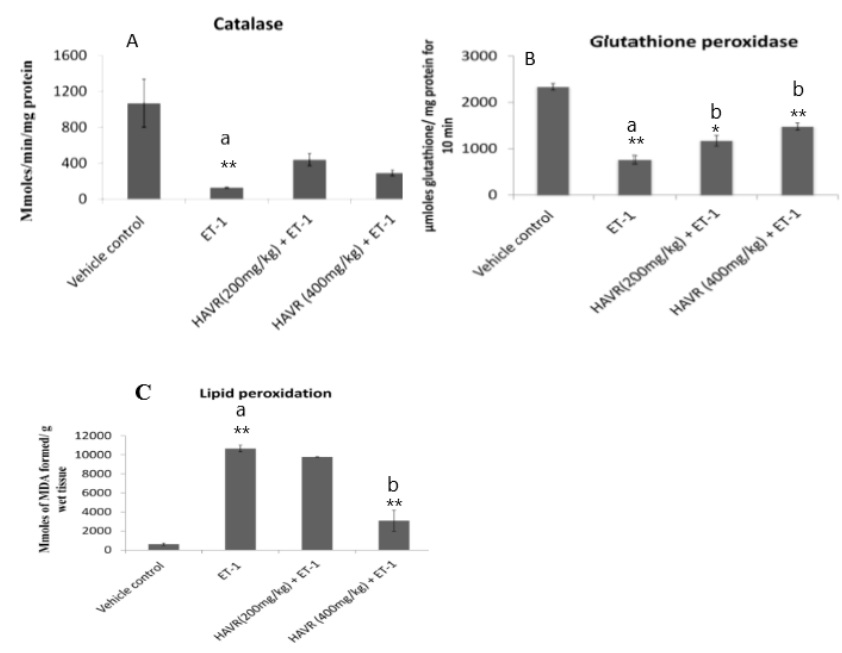

Figure 5: Antioxidant tests performed in vehicle control, ET-1 control and ET-1 +HAVR drug (200 and $400 \mathrm{mg} / \mathrm{kg}$ ) treatment groups. The assessments of effect of HAVR on antioxidant property in brain homogenate by estimating Catalase (A), Glutathione peroxidase (B) and Lipid peroxidation (C) are shown respectively. HAVR- Hydro alcoholic extract of Vanda roxburghii.

${ }^{*} p<0.01,{ }^{*} p<0.05$, a- in comparison with vehicle control, b- in comparison with ET-1 control.

revealed that the ET-1 injection into the hippocampal area significantly reduced the percentage survival of pyramidal neurons in both CA1 and CA3 regions as compared to vehicle control (Figure 4, CA1, compare B with A, I). Both the 200 and $400 \mathrm{mg} / \mathrm{kg}$ doses of HAVR significantly attenuated the ET-1-induced neuronal loss in the hippocampal CA1 region (Figure 4, compare C and $\mathrm{D}$ with $\mathrm{B}, \mathrm{I})$. The percentage survival of cells in the CA3 region in the HAVR treated groups were significantly improved as compared to the ET-1 group (Figure 4, compare $\mathrm{G}$ and $\mathrm{H}$ with F, J).

\section{Effect of HAVR on antioxidant levels in oxidative stress induced by ischemic hippocampal injury}

ET-1 induced ischemic hippocampal injury caused significant increase in the lipid peroxidation as compared to the vehicle control (Figure 5C). HAVR at $400 \mathrm{mg} / \mathrm{kg}$ treatment attenuated of oxidative stress response in ischemic rats, as noted by the significant reduction in lipid peroxidation level. (Figure 5C). Ischemic hippocampaldamagealsoled a significantdownregulation of antioxidant enzyme activities such as glutathione peroxidase (Figure 2B) and catalase (Figure 5B). HAVR drug administration, both at low and high doses revealed a significant preservation of hippocampal glutathione peroxidase levels in ischemic conditions (Figure 5B). However, catalase activity was not affected at both doses of HAVR treatment (Figure 5A).

\section{DISCUSSION}

In the present study there was significant reduction in the CAT, GSH-Px and increased lipid peroxidation in Endothelin-1 induced ischemic stroke group as compared to vehicle control. During ischemia stroke, high energy phosphate levels such as ATP, GTP were hydrolyzed into Adenosine monophosphate (AMP) and Guanosine monophosphate (GMP), which leads to profound disturbance in cell electrolyte balance. It has been noted that the loss of cellular high energy compounds (ATP and GTP) causes the loss of the $\mathrm{Na}^{+}-\mathrm{K}^{+}$ gradient; it may cause a massive influx of calcium ions into the cells. Mitochondrial sequestration causes calcium $\left(\mathrm{Ca}^{+}\right)$overloading and diminished capacity of phosphorylation. Thus elevated intracellular calcium activates membrane phosphorylation and protein kinase, which inturn increase prostaglandins and arachidonic acid. Cytokines causes generation of reactive oxygen species (ROS), platelet aggregation, vasospasm, clotting and edema which results in to compromise to restore of adequate cerebral perfusion and severe oxidative stress. Intracellular calcium in the neurons triggers the production of nitric oxide (NO) that can diffuse to adjacent neurons and causes nitric oxide toxicity. Thus when nitric oxide combines with superoxide's toxic nitrates were produced that can cause membrane lipid peroxidation..$^{31-34}$

Several research studies showed that the medicinal plants extracts can be used for the treatment of brain ischemia and reperfusion injury. The extract of Ginkgo biloba protects brain neurons against oxidative stress and rescues the neurons following ischemic reperfusion injury. ${ }^{35}$ Pretreatment with G. biloba extract significantly reduced the brain edema in the hippocampal area in a dose dependent manner. ${ }^{36}$ Ocimum basilicum extract was evaluated for neuroprotective activity in the transient global cerebral ischemia and reperfusion injury. The neuroprotection was caused by significant reduction in the lipid peroxidation and restoration of endogenous antioxidants with reduction in the infarct size. ${ }^{37}$

Thus medicinal plants can play potential role in the management of ischemic stroke. In the present study, ET-1 injection readily produced and significant reduction in the anti-oxidant enzymes and elevation in the lipid peroxidation by ischemic reperfusion injury, while treatment with HAVR significantly attenuated the lipid peroxidation by reducing TBARS concentration. This shows that the HAVR may have a potential to overcome either generation of ROS or scavenging formed ROS in the hippocampus. It may also have a role in maintaining the calcium homeostasis. 
The hippocampal cells are highly vulnerable to ischemic insults which could affect its structural and functional integration and may lead to spatial cognition deficits. ${ }^{38}$ The studies indicated, ET-1 readily induced tissue loss in the CA1 and CA3 regions of hippocampus and hence the observed behavioral decline following ET-1 induced stroke supports the view that hippocampal sub areas like CA1 and CA 3 regions play a central role in the learning and memory process and cognitive functions. Several studies demonstrated the involvement of cells of Cornu Ammonis (CA1 and CA3) and dentate gyrus (DG) regions of hippocampus in spatial representation. ${ }^{39}$

In the present study, ET-1 administration caused considerable decrease in the total locomotor activity in the Actophotometer test. Earlier researchers reported that the hippocampal damaged rats showed significant increase in the locomotion after treatment with dopamine (D1 and D2) receptor agonists when compared to rats of control group. These findings provided an evidence of hippocampal modulation of locomotion and involvement of dopaminergic mechanism. ${ }^{40} \mathrm{We}$ observed a significant increase in the locomotor activity after treatment with HAVR at higher doses as compared to ischemic stroke group. This shows the HAVR drug may have a modulator role in the hippocampal dopaminergic circuitry.

\section{CONCLUSION}

The present investigations unraveled the neuroprotective effect and also favor the evidence for the therapeutic role against focal ischemia in rats. Analysis of the overall results shows that HAVR possess considerable antioxidant, neuroprotection and memory impairment reversal effects.

\section{Compliance with ethical standards}

All applicable international, national and/or institutional guidelines for the care and use of animals were followed. All procedures performed in studies involving animals were in accordance with the ethical standards of the institution or practice at which the studies were conducted.

\section{ACKNOWLEDGEMENT}

The authors are highly grateful to Chairman of DM WIMS, Wayanad, India for his constant motivation to carry out this research work and Dr. Antony Sylvan D' Souza, Dean, DM WIMS, Wayanad, Kerala, India for his constant support. The authors acknowledge King Saud University, Riyadh, Saudi Arabia, for funding this work through Researchers Supporting Project number (RSP-2019/11).

\section{CONFLICT OF INTEREST}

The authors declare no conflict of interest.

\section{ABBREVIATIONS}

HAVR: Hydro alcoholic extract of Vanda roxburgbii; MCAO: Middle cerebral artery occlusion; ROS: reactive oxygen species; CAT: Catalase; GSH-Px: Glutathione peroxidase; SOD: Superoxide dismutase; nitric oxide: NO, TBARS: Thiobarbituric acid reactive substances; MDA: Malondialdehyde; CNS: Central nervous system; $\mathbf{H}_{2} \mathbf{O}_{2}$ : Hydrogen peroxide; CA: Cresyl violet; CA1: Cornu ammonis 1; CA3: Cornu ammonis 3; AMP: Adenosine monophosphate; GMP: Guanosine monophosphate: ANOVA: Analysis of variance; SEM: Standard error of mean.

\section{REFERENCES}

1. Dirnagl U, ladecola C, Moskowitz MA. Pathobiology of ischaemic stroke: an integrated view. Trends Neurosci. 1999;22(9):391-7.

2. Sachdev PS, Chen X, Joscelyne A, Wen W, Altendorf A, Brodaty H. Hippocampal size and dementia in stroke patients: the Sydney stroke study. J Neurol Sci. 2007;260(1-2):71-7.

3. Iadecola C, Alexander M. Cerebral ischemia and inflammation. Curr Opin Neurol. 2001;14(1):89-94.

4. Langdon KD, Maclellan CL, Corbett D. Prolonged 24-h delayed peripheral inflammation increases short- and long-term functional impairment and histopathological damage after focal ischemia in the rat. J Cereb Blood Flow Metab. 2010;30(8):1450-9.

5. Lakhotia SC. Neurodegeneration disorders need holistic care and treatment: Can Ayurveda meet the challenge?. Ann Neurosci. 2013;20(1):1-2.

6. Srivastava P, Shanker K. Chemical and biological potential of Rasayana herb used in traditional system of medicine. Fitoterapia. 2012;83(8):1371-85.

7. Kirtikar KR, Basu BD. Indian Medicinal Plants. $2^{\text {nd }}$ ed. Dehradun, India: International Book Distributors.1999.

8. Kumara NK. Identification of strategies to improve research on medicinal plants used in Sri Lanka. In WHO Symposium, University of Ruhuna, Sri Lanka. 2001;12-4

9. Ghani A. Medicinal plants of Bangladesh with Chemical Constituents and uses. $2^{\text {nd }}$ ed. Dhaka: Asiatic Society of Bangladesh. 2003;424.

10. Pathan D, Ambavade S. Investigation of anticonvulsant activity of Vanda roxburghii. Journal of Pharmacognosy and Phytochemistry. 2014;2(6):95-9.

11. Rastogi RP, Mehrotra BN. Compendium of Indian Medicinal Plants. Lucknow: Central Drug Research Institute.1990.

12. Basu K, Das GB, Bhattacharya SK, Lal R, Das PK. Anti-inflammatory principles of Vanda roxburghii. Cur Sci. 1971;40:86-7.

13. Chawla AS, Sharma AK, Handa SS, Dhar KL. Chemical studies and antiinflammatory activity of Vanda roxburghii root. Indian J Pharm Sciences. 1992;54:159-61.

14. Ahmed F, Sayeed A, Islam A, Salam SA, Sadik G, Sattar MA. Antimicrobial activity of extracts and a glycoside from Vanda roxburghii Br. Pak J Biological Sciences. 2000;5(2):189-91.

15. Nayak BS, Suresh R, Rao AV, Pillai GK, Davis EM, Ramkissoon V. Evaluation of wound healing activity of Vanda roxburghii $\mathrm{R}$. $\mathrm{Br}$ (Orchidacea): A preclinical study in a rat model. Int J Low Extrem Wounds. 2005;4(4):200-4.

16. Prasad DN, Achari G. A study of anti-arthritic action of Vanda roxburghii in albino rats. J Indian Med Assoc. 1986;46(5):234-7. 
17. Subramoniam A, Gangaprasad A, Suresh KPK, Radhika J, Arun BK. A novel aphrodisiac compound from an orchid that activates nitric oxide synthases. Int J Impotence Res. 2013;25(6):212-6.

18. Uddin MN, Rejina A, Uddin MJ, Aziz AR, Golam S. Vanda roxburghii chloroform extract as a potential source of polyphenols with antioxidant and cholinesterase inhibitory activities: identification of a strong phenolic antioxidant. BMC Complement Altern Med. 2015;15(1):195.

19. Fuxe K, Bjelke B, Andbjer B, Grahn H, Rimondini R, Agnati LF. Endothelin- 1 induced lesions of the front parietal cortex of the rat. A possible model of focal cortical ischemia. Neuro Report. 1997;8(11):2623-9.

20. Tsenov G, Mateffyova A, Mares P, Otahal J, Kubova H. Intrahippocampal injection of endothelin-1: A new model of ischemia-induced seizures in immature rats. Epilepsia. 2007;48:7-13

21. Hughes PM, Anthony DC, Ruddin M, Botham MS, Rankine EL, Sablone M, et al. Focal lesions in the rat central nervous system induced by endothelin-1. J Neuropathol Exp Neurol. 2003;62(12):1276-86.

22. Suresh $\mathrm{SN}$, Chavalmane AK, Yarreiphang $\mathrm{H}$, Manjithaya R. A novel autophagy modulator 6-Bio ameliorates SNCA/alpha-synuclein toxicity. Autophagy. 2017;13(7):1221-34.

23. Bansinath $M$, Bose AC, Hema S, Guruswami MN. Interaction of metamizol with some hypnotics in rats. Arch Int Pharmacodyn Ther. 1982;260(1):14-27.

24. Bromley BK, Deng Y, Song W. Morris water maze test for learning and memory deficits in Alzheimer's disease model mice. J Vis Exp. 2011;20(53):2970.

25. Vorhees CV, Williams MT. Morris water maze: Procedures for assessing spatial and related forms of learning and memory. Nat Protoc. 2006;1(2):848-58.

26. Kelley B, Yu D, Weihong S. Morris water maze test for learning and memory deficits in Alzheimer's disease model mice. Experiments. 2011;20(53): 2920.

27. Sinha AK. Colorimetric assay of catalase. Anal Biochem. 1972;47(2):389-94.

28. Ohkawa H, Ohishi N, Yagi K. Assay for lipid peroxides in animal tissues by thiobarbituric acid reaction. Anal Biochem. 1979;95(2):351-8.
29. Rotruck JT, Pope AL, Ganther HE, Swanson AB, Hafeman DG, Hoekstra WG. Selenium: Biochemical role as a component of glutathione peroxidase. Science. 1973;179(4073):588-90.

30. Bancroft JD, Stevens A. Pigments and minerals. Theory and practice of histological techniques. New York, Churchill Livingstone. 1999;262.

31. Raichle ME. The pathophysiology of brain ischemia. Annals of Neurology. 1983;13(1):2-10.

32. Mullane KM, Salmon JA, Kraemer R. Leukocyte derived metabolites of arachidonic acid in ischemia-induced myocardial injury. Fed Proc. 1987;46(7):2422-33.

33. Tien M, Aust SD. Comparative aspects of several models of lipid peroxidation systems. Initiation of Lipid Peroxidation in Biology and Medicine, Academic press, New York. 1992;23-39.

34. McCord JM. Oxygen derived free radicals in post ischemic tissue injury. N Engl J Med. 1985;312(3):159-63.

35. Spinnewyn B, Blavet N, Clostre F. Effects of Ginkgo biloba extract on a cerebral ischemia model in gerbils. Presse Med. 1986;15:1511-5.

36. Calapai G, Crupi A, Firenzuoli F, Marciano FC, Squadrito F, Inferrera G. Neuroprotective effects of Ginkgo biloba extract in brain ischemia are mediated by inhibition of nitric oxide synthesis. Life Sci. 2000;67(22):2673-83.

37. Bora KS, Arora S, Shri S. Role of Ocimum basilicum L. in prevention of ischemia and reperfusion-induced cerebral damage and motor dysfunctions in mice brain. J Ethnopharmacol. 2011;137(3):1360-5.

38. Faraji J, Soltanpour N, Moeeini R, Roudaki S, Soltanpour N, Abdollahi AA, et al. Topographical disorientation after ischemic mini infarct in the dorsal hippocampus: whispers in silence. Front Behav Neurosci. 2014;8:261.

39. Enrico $\mathrm{C}$, Richard $\mathrm{M}$. The $\mathrm{CA} 3$ region of the hippocampus; how is it? What is it for? How does it do it?. Front Cell Neurosci. 2015;9:1-3.

40. Guy M, Patricia AL, lan W. The role of D1 and D2 receptors in the heightened locomotion induced by direct and indirect dopamine agonists in rats with hippocampal damage: An animal analogue of schizophrenia. Behav Brain Res. 1993;55(2):253-67.

\section{PICTORIAL ABSTRACT}

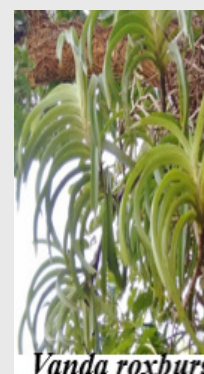

Vanda roxburghit plant

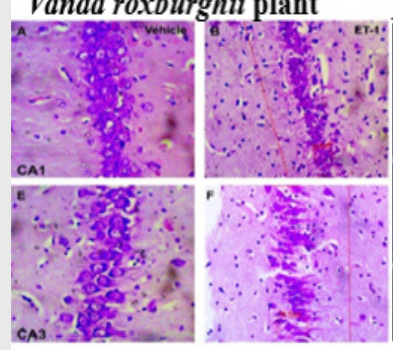

Hippocampal CA1 and CA3 pyramidal cells

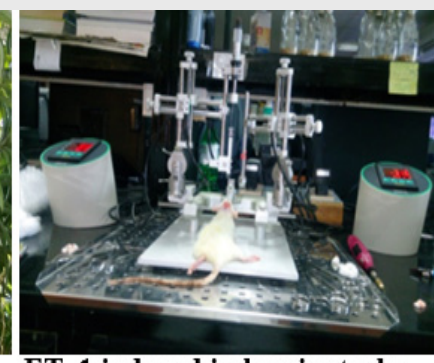

ET- 1 induced ischemic stroke

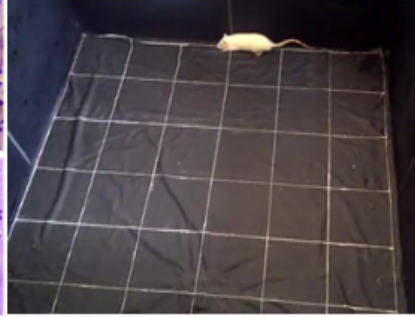

Open field behaviour study

\section{.}

- Delayed neuronal death in the CA1 and CA3 regions of hippocampus was significantly attenuated by higher dose of the Vanda roxburghii extracts.

- Vanda roxburghii plant holds potentials for treating pathological consequences of ischemic stroke and associated cognitive abnormalities. 


\section{About Authors}

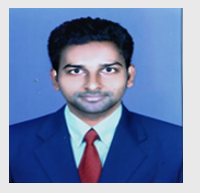

Dr. Ravi Mundugaru is working as Assistant Professor in the Department of Pharmacology at DM Wayanad Institute of Medical Sciences, Wayanad, Kerala, India. He is MSc in Medical Pharmacology from Manipal University, Manipal and PhD in Neuropharmacology from Saveetha University, Chennai. He is investigating AYUSH-EMR projects on safety evaluation of two important Herbomineral formulations used in the Ayurvedic practice. And Co investigators in four project sponsored by Rajiv Gandhi University of Health Sciences, Bangalore. His field of expertise includes in vitro and in vivo assays in Pharmacology and Toxicology, cell and molecular biology. He is Author of 52 research papers in national and international peer reviewed journals.

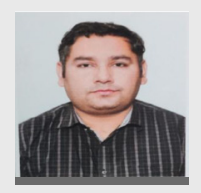

Dr. Sukrant Sharma, Assistant Professor in the P.G Department of Shalya tantra in Jammu Institute of Ayurveda and Research. He has done his B.A.M.S from Dayanand Ayurvedic College, Punjab \& M. S(Ayu) from SDM College of Ayurveda \& Hospital, Udupi, Karnataka. He has presented Scientific Paper's in National \& International Seminars. He is Author of 14 Clinical and experimental research articles in National and International Peer Reviewed Journals

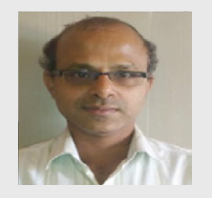

Dr. S. Senthilkumar has obtained Ph.D in Biochemistry/Bioorganic Neurochemistry from University of Madras, Chennai and pursued Postdoctoral research training at E-M-A University of Greifswald, Germany, lowa State University and Stanford University School of Medicine, USA. He is presently working as Associate Professor in the Department of Research and Development, Saveetha Institute of Medical and Technical Sciences, Chennai, India. His research focuses on the pathogenesis of neurological diseases such as Alzheimer's, Parkinson's and Stroke and developing therapeutics. He has published more than 30 research papers in refereed journals and has been serving as reviewer for many neuroscience related journals. He is a guest editor for the Journal Biochemistry Insights.

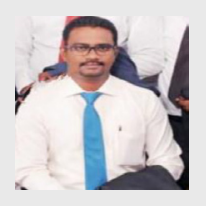

Dr. Rajesh Thangarajan is an Associate Professor in the Dept. of Anatomy, Melaka Manipal Medical College, Manipal, India. He obtained his Ph.D in Anatomy from Manipal University. He has presented Scientific Paper's in National \& International Seminars. He is Author of 15 research articles in National and International Peer Reviewed Journals.

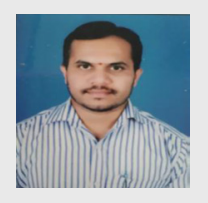

Dr. Pundalik Rama Naik is working as Tutor in the Department of Biochemistry, Kodagu Institute of Medical Sciences, Kodagu, Karnataka, Inidia. He has done his M.Sc Medical Biochemistry from JSS, Mysore, Karnataka. He has presented Scientific Paper's in National \& International Seminars. He is Author of 3 research articles in National and International Peer Reviewed Journals.

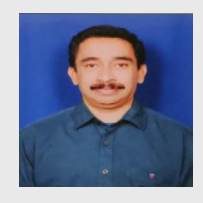

Dr. Nagesh Raju is a Professor in the Department of Pharmacology at DM Wayanad Institute of Medical Sciences, Wayanad, Kerala, India. He has 20 years of experience in the field of Pharmacology. He is Author of 18 research articles in National and International Peer Reviewed Journals.

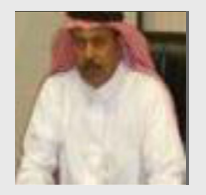

Dr. Ahmed Alfarhan is a Professor in the Dept. of Botany and Microbiology, College of Science, King Saud University, Riyadh, Saudi Arabia. He obtained his Ph.D in Botany from University of Reading, England. He is an expert in plant taxonomy, ecophysiology and bioprospecting. He has published more than 200 research papers in various peer reviewed journals and also authored many books. His research group is active in research related to medicinal plants. 


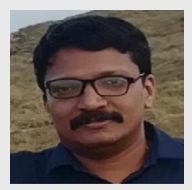

Dr. Rajakrishnan Rajagopal is working as Researcher in the Department of Botany and Microbiology, College of Science, King Saud University, Riyadh, Saudi Arabia. He obtained a Ph.D degree in Botany from Manonmaniam Sundaranar University, Tirunelveli. He is specialized in ethnopharmacology, ecophysiology as well as floristic studies. He has published many research papers in referred journals.

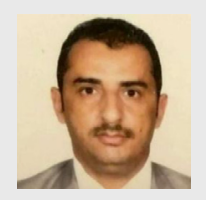

Bander Al-Munqedhi is a Research Scholar in the Department of Botany and Microbiology, College of Science, King Saud University, Riyadh, Saudi Arabia. His research focuses on environmental biology and bioprospecting of plants.

Cite this article: Mundugaru R, Sharma S, Sivanesan S, Thangarajan R, Naik PR, Raju N, Alfarhan A, Rajakrishnan R, AIMunqedhi B. Neuroprotective Effects of Vanda roxburghii Extract in Endothelin-1 (et-1) Induced Hippocampal Ischemic Damage and Ameliorate Cognitive Deficit. Indian $\mathrm{J}$ of Pharmaceutical Education and Research. 2020;54(3):740-9. 